\title{
La cohesion social y la teoria de la congruencia: Latinoamérica una región dividida.
}

\author{
Social Cohesion and Congruence Theory: Latin America, a divided \\ region
}

Fernando Duque

\section{Resumen}

Se analiza la baja cohesión social en Latinoamérica. Se señalan varios indicadores de este fenómeno, tales como la crónica inestabilidad política, la ola de criminalidad que invade la región y la emigración hacia regiones más desarrolladas. Se argumenta que la causa principal de la baja cohesión social es una incongruencia sistémica entre el subsistema cultural por un lado y los subsistemas políticos y económicos por otro. A comienzos del siglo XXI, esta incongruencia ha hecho crisis y muchos paises del planeta han comenzado un proceso para reducirla, siendo Rusia uno de los países más destacados. En América Latina también se ha iniciado un proceso revolucionario siendo Cuba y Venezuela los líderes de este movimiento.

Palabras claves: Cohesión social, Sistema, Teoría de la Congruencia.

\begin{abstract}
The lack of social cohesion in Latin America is the subject of this paper. Several indicators of this phenomenon are presented here, such as the chronic political instability, the wave of criminality and the emigration to more developed regions. It is argued that the principal cause of the phenomenon is the systemic incongruence between the cultural subsystem in one hand and the political and economic subsystems in the other. At the beginning of the XXI century this incongruence entered in a critical point. Many countries of the planet are in the process of solving this incongruence, being Russia the most emblematic country of this process. In Latin America the process has also began, being Cuba and Venezuela the leaders of this new revolutionary movement.
\end{abstract}

Keywords: Social cohesion, systems, congruency theory.

\section{Introducción}

Recientemente se desarrolló en Chile una reunión de la cumbre iberoamericana y el tema principal de ésta, era la cohesión social en la región. Este tema se eligió precisamente porque existe una crisis en las relaciones entre países de la región y también en las relaciones sociales dentro de cada país. La división social y sus terribles efectos se hacen claramente evidentes desde el río Grande hasta la Patagonia. Los conflictos políticos y sociales no pueden ser resueltos mediante el diálogo, la negociación y la búsqueda de consensos básicos.

En forma cada vez más frecuente las imágenes que se ven por la televisión en casi todos los países de la región reflejan grupos de ciudadanos protestando en las calles, las protestas se vuelven violentas e invariablemente la policía y a veces la fuerza armada entran en conflicto, dejando heridos y muertos. La represión gubernamental se impone y se vuelve una calma aparente. La violencia abierta y colectiva es remplazada por una violencia más oculta y privada que se manifiesta en una ola de criminalidad, drogadicción, enfermedades mentales y violencia intra familiar. En muchos casos los ciudadanos más perjudicados con el actual sistema de gobierno y economía se sumen en una apatía generalizada y no pocos optan por abandonar la región y emigrar a países más civilizados.

- Doctor en Ciencia Política Universidad de California (Los Ángeles). Trabajó por 20 años como jefe de proyectos de Naciones Unidas en el área del desarrollo de la Administración Pública en Centro América, África y Asia. Actualmente se desempeña como profesor titular en Ciencias Politica en la Universidad de Los Lagos, Campus Chinquihue. Ubicación: Camino Chinquihue Km 6 - Puerto Montt, Chile .E-mail: fduque@ulagos.cl

Artigo submetido em dezembro de 2007 e aceito em agosto de 2008 
Es necesario identificar cuáles son los factores o causas que determinan la violencia. Una causa importantísima es la falta de cohesión social, ésta se ha definido como un fuerte sentimiento de simpatía, fraternidad y amistad hacia otros individuos pertenecientes a una misma sociedad. $\mathrm{Y}$ este sentimiento se produce porque a los otros se les identifica como individuos pertenecientes a un mismo sistema de valores y se les convierte en nosotros. Se les trata con respeto y decencia porque ellos son parte importante de la propia identidad. En otras palabras, son miembros de una misma comunidad. Esta cohesión social es un cemento poderoso que une a la sociedad e impide que las diferencias políticas, sociales o económicas produzcan violencia, caos y destrucción. Podría decirse metafóricamente que la comunidad es como un edificio muy bien construido con hierro reforzado, concreto armado y base de apoyo anclada en roca profunda. De esta manera el edificio es capaz de resistir sin destruirse violentos terremotos y huracanes.

El trabajo continúa con un esfuerzo por explicar los factores y variables que determinan la existencia o inexistencia de la cohesión social en un país o región determinada. Se argumenta que un factor determinante de esta cohesión es el grado de congruencia que existe entre el sistema cultural que una sociedad tiene y la manera de producir, consumir y gobernar que ella posee. Se dice que la cohesión social existe en aquellas sociedades donde hay compatibilidad, semejanza y adaptabilidad entre el núcleo fortalecido por los valores culturales que la sociedad tiene y el sistema político y económico que esa sociedad utiliza para avanzar en su proceso de desarrollo civilizacional .

El trabajo continua señalando, que algunos pueblos de la región han reaccionado ante la situación de caos y violencia y han elegido líderes cuyo programa político es acabar con el sistema neoliberal. Es así como surge el fenómeno de Chávez en Venezuela, Morales en Bolivia, Correa en Ecuador, Kirchner en Argentina, Lula en Brasil, Vásquez en Uruguay y Ortega en Nicaragua. Por su parte Cuba consolida su sistema socialista y la guerrilla marxista se consolida en Colombia. Por otro lado en México y Perú, líderes anti liberales estuvieron cerca de alcanzar el poder y seguramente van a seguir en su intento por alcanzarlo en los próximos años. Finalmente toda la región centroamericana ha entrado nuevamente en ebullición y es cuestión de tiempo para que el volcán nuevamente explote. Aparentemente, sólo la elite chilena se mantiene fiel a sus valores neoliberales, pero aún aquí ya existen signos de divisiones importantes.

El trabajo finaliza haciendo un breve análisis de los cambios radicales que se están produciendo en Rusia, se señala que en ese país así como en otros países de la ex Unión Soviética, se están convirtiendo en formas de gobierno y economías compatibles y congruentes con su carácter nacional.

\section{Desarrollo}

No hay unidad ni cohesión social en el continente latinoamericano. Y debido a este fenómeno es que ésta es una de las regiones más conflictivas del planeta. Tal es el descalabro social, que una gran cantidad de sus ciudadanos tratan de escapar a países más desarrollados como los Estados Unidos, Canadá, Australia y Europa Occidental. Ni siquiera los líderes de la región son capaces de mantener las apariencias de unidad. La cumbre iberoamericana que acaba de realizarse en Santiago, es una muestra de este fenómeno. Los presidentes Kirchner y Vásquez casi produjeron un conflicto diplomático. Chávez desde su llegada manifestó que hablar de cohesión social en las actuales condiciones del continente era una soberana estupidez. El presidente Morales demostró su desprecio al tema abandonando funciones oficiales y prefiriendo jugar un partido de fútbol. Y para cerrar con broche de oro, en la sesión de clausura varios presidentes arremetieron contra España. Chávez acusó a Aznar de víbora peligrosa y de fascista. Correa acusó a España de ser racista y los presidentes Ortega y Kirchner señalaron que los españoles eran explotadores y abusadores. Para colmo, el rey perdió el control y finalizó la reunión.

Se entiende por Cohesión Social, un generalizado sentimiento de unidad, simpatía y fraternidad, compartido por los miembros de una sociedad determinada. Es como el sentimiento que se da en una gran familia extendida. Esto es producto de una evolución histórica común, un lenguaje común, y valores religiosos compartidos. Ello implica una identidad donde los valores culturales son aceptados y respetados por las inmensas mayorías. También implica una visión de mundo común (IMAGO MUNDI), y un destino hacia donde la sociedad quiere llegar en el futuro. Diametralmente opuesta a la cohesión social está el concepto de 
división social y lucha de clases, ampliamente analizado por los marxistas. Aquí no hay consenso y compromiso posible, y la sociedad inexorablemente se mueve hacia la confrontación.

Vale la pena preguntarse cuales son las probables causas de esta tragedia continental. Una causa inmediata importante es la frustración provocada por la actual desigualdad en el ingreso y la riqueza y la enorme brecha que existe entre ricos y pobres. Esta desigualdad profunda crea lo que los científicos sociales han denominado "privación relativa". La gente no compara su ingreso o riqueza con el de sus padres o abuelos. Pero sí lo compara con el ingreso actual de sus contemporáneos (vecinos, amigos) y sobre todo, con el estándar de vida de la elite que se ve todos los días en la televisión. El descubrimiento de que los perdedores no son pocos, sino la inmensa mayoría, produce rabia y malestar malamente controlado y que por lo general explota en forma irracional. Un simple partido de fútbol, o esperas prolongadas a la locomoción colectiva, una huelga mal manejada o una manifestación callejera, se transforman en verdaderas batallas campales donde hay muertos y heridos. Estas son las manifestaciones colectivas de la enfermedad social. Las manifestaciones privadas son mucho más extendidas y ellas se manifiestan en violencia intra familiar, la drogadicción, la criminalidad, el alcoholismo, la inseguridad ciudadana y una feroz crítica a todo lo que las elites producen.

Entre las causas remotas de esta falta de cohesión social, puede señalarse el fracaso del modelo liberal en Iberoamérica, que lleva casi doscientos años y los resultados son la riqueza para muy pocos y el subdesarrollo y la pobreza para la gran mayoría, todo esto en una región que concentra una altísima proporción de los recursos naturales del planeta. El modelo ha fracasado por lo que denomina "la incongruencia", entre el sistema económico y el sistema cultural. Para que el modelo liberal funcione, se necesita como condición suficiente y necesaria, la existencia de una masa crítica de individuos con una mezcla de la cultura democrática (Homos Democraticus) y de cultura empresarial (Homos Economicus). Esta masa crítica es la que sustenta el buen funcionamiento del modelo capitalista democrático en los países desarrollados de occidente. Estas precondiciones de la democracia fueron analizadas extensivamente por Sócrates, Platón y particularmente Aristóteles hace mas de 2.500 años atrás.

Como Iberoamérica no tiene una masa crítica de individuos dotados de estas características culturales, el capitalismo de la región es premoderno y subdesarrollado. La clase empresarial es del tipo pre-moderna, busca el lucro fácil y rápido a toda costa, aunque esto sacrifique la calidad de los productos, el medio ambiente, el salario de los obreros y la cohesión social. Esta conducta está muy lejos de los principios éticos propuestos por la filosofía liberal particularmente enunciadas por Locke, Montesquieu, Voltaire, Russeau, Smith, Ricardo, Mill, Weber, Schumpeter, Dahl, Almond, Huntington, Eckstein y tantos otros filósofos y científicos políticos, proponentes del modelo liberal, el capitalismo moderno y la democracia. La elite se identifica con el consumo de las elites de países desarrollados, pero teme y desprecia odiosamente a las grandes masas populares. Las masas a su vez responden con envidia, odio y desprecio hacia las elites. Ante todo esto la cohesión social deja de existir y la sociedad se encamina hacia una confrontación social inevitable.

En forma sumamente abreviada, la Teoría de la Congruencia en ciencia política (primero elaborada por los clásicos principalmente Aristóteles, pero que ahora su mayor exponente es Harry Eckstein), señala que una sociedad es congruente cuando su sistema económico y político es altamente compatible con los valores dominantes de su sistema cultural. En otras palabras, las formas de producir y consumir, así como también las formas de gobernar, están sólidamente basadas en valores culturales que se han desarrollado a través de siglos y milenios. Así, por ejemplo, la sociedad noruega tiene una alta congruencia entre sus valores democráticos y el sistema económico y político que ese país tiene. Los noruegos aman la libertad y también aman la igualdad. Tienen respeto y obedecen a normas conducentes a la democracia y que a la vez aseguran la buena gobernabilidad. Hay respeto hacia el conocimiento, la especialización y la experiencia. Las decisiones se toman razonadamente y por consenso y no por imposición autoritaria. Es así como la familia, la escuela, la fábrica, el sindicato, la oficina, la iglesia y así, todas las estructuras sociales primarias son semi-democráticas. Por otro lado, las estructuras no gubernamentales del sistema político, tales como los grupos de presión, los partidos políticos y la prensa, se conducen definitivamente bajo prácticas democráticas. Todo esto determina que el resto de las estructuras del sistema político también sean democráticas y funcionen muy bien. Los poderes legislativo, ejecutivo y judicial funcionan adecuada y democráticamente. Por otro lado, la ética de trabajo protestante (amor por el trabajo productivo, propensión al ahorro, a la inversión y la filantropía) también es 
congruente con la economía social demócrata de los noruegos y por eso funciona apropiadamente. Naturalmente, aquí se da una cohesión social sumamente robusta.

Otro sistema igualmente congruente es el cubano. El sistema político y económico cubano también es coherente con su cultura. Ellos, por su tradición histórica, prefieren el liderazgo centralizado y paternalista de un solo líder (gobierno de uno) y por lo tanto son autoritarios. Tienen motivaciones y valores altamente proclives al trabajo colectivo y a la distribución equitativa de la riqueza. Prefieren y enfatizan la igualdad y la justicia social por sobre la libertad individual. Consecuentemente, aquí también existe una alta congruencia entre sistema político y económico con el sistema cultural y ella determina el buen funcionamiento de la sociedad cubana. Aquí también existe una fuerte cohesión social.

La teoría de la congruencia ha empezado a entenderse en América Latina. Por doscientos años la región ha tenido un sistema liberal de gobierno y economía, pero debido a una fundamental incongruencia entre este sistema y la cultura y civilización latinoamericana, este ha sido un rotundo fracaso. Ahora las sociedades latinoamericanas están cuestionándose este modelo a fondo. Por miles de años la región se desarrolló bajo un sistema de gobierno autoritario y una economía colectivista. Estas características se incrustaron aun más en el alma de la región durante los trescientos años del imperio español. Ahora, a comienzos del siglo XXI, sus pueblos y líderes están afanosamente trabajando por extirpar el cáncer de la incongruencia. Paulatinamente se ha ido dejando el modelo liberal y adoptando un modelo que mucho se asemeja al sistema monárquico discutido y analizado por Sócrates, Platón y Aristóteles (gobierno de uno, pero en beneficio de todos).

Sin embargo, esta nueva "monarquía" no tiene filósofos reyes hereditarios, sino monarcas temporales apoyados por la mayoría de la ciudadanía. La condición básica para que estos monarcas temporales tengan éxito, es que ellos gobiernen en beneficio de las grandes mayorías y el interés común. El monarca temporal puede seguir en el poder si hace bien su trabajo. Su periodo de gobierno se extiende indefinidamente si el pueblo lo respalda con elecciones populares o con las fuerzas de las armas o mejor aún, con ambas características.

Naturalmente este ha sido el caso de Cuba desde 1959 y hoy parece ser el caso de Venezuela. A largo plazo candidatos para esta nueva forma de gobierno son: Argentina, México, Colombia, Brasil, Paraguay, Bolivia, Ecuador y Centro América. La monarquía temporal y popular sí es congruente con los valores fundamentales de la cultura iberoamericana. Ella tiene sus profundas raíces incrustadas en la historia de la región. Por miles de años, antes del siglo $\mathrm{XV}$, la región fue gobernada por los filósofos reyes de las civilizaciones azteca, maya y andina. Luego, esta tradición continúa por trescientos años más bajo el imperio español. Puede así decirse que las seudo repúblicas oligárquicas liberales han sido sólo un aberrante paréntesis histórico y que la región esta gradualmente volviendo a sus tradiciones ancestrales. Si las monarquías temporales y populistas tienen éxito, pronto todo el continente habría vuelto a la senda de un proceso de evolución civilizacional interrumpido a comienzos del siglo XIX.

La división social aguda (unos poquísimos ricos y un océano de pobres) que sufre la región es producto directo del cáncer de la incongruencia, es decir, la incompatibilidad entre el sistema político-económico aún dominante con el sistema cultural. Las nuevas monarquías temporales y populistas están eliminando dicha incongruencia y volviendo a un sistema político paternalista y autoritario, y también a la economía colectivista, estatista e intervensionista, que por miles de años fue el sistema natural de América Latina. Sólo este nuevo sistema monárquico populista podrá ser capaz de recuperar la cohesión social a la que aspiran los pueblos al sur del río Grande. Este sistema político sí que es altamente congruente con la historia y los valores fundamentales de la civilización latinoamericana.

El larguísimo proceso de modernización de una sociedad implica un cambio traumático, drástico, brutal, y sostenido por varias generaciones. La sociedad deja de ser rural y gradualmente se transforma en urbana. La agricultura tradicional de subsistencia es reemplazada por la industria y los servicios. Los ciudadanos dejan de ser ciudadanos analfabetos y se transforman en personas capaces de aprender, observar y comprender su entorno y circunstancia. La salud mejora sustancialmente y gracias a ello aumenta drásticamente la población. El acelerado proceso de desarrollo económico, aumenta y mejora gradualmente el estándar de consumo de las personas $\mathrm{y}$, por lo tanto, incrementa su riqueza material. 
Pero este progreso material evidente ocasiona un costo sicológico terrible y devastador para la psiquis colectiva de las generaciones que sufren el proceso modernizador. La antigua y sólida protección tribal que brinda la vida campesina se pierde totalmente Los lazos de la familia extendida se cortan, las amistades se interrumpen y las raíces se arrancan. El ser humano urbanizado se hunde en una inmensa y angustiosa soledad, rodeado de masas de individuos igualmente solos y angustiados. Naturalmente, reconoce que tiene más riqueza material que sus padres, abuelos y antepasados originarios, pero esto no es consolación alguna. El individuo arrastrado por el proceso de modernización se compara sólo con sus pares actuales. Es decir, vecinos, conocidos, compañeros de trabajo, y sobretodo con la elite, cuya vida fastuosa y llena de riqueza observa todos los días en la televisión. Descubre que los ganadores en este proceso modernizador son poquísimos y que la inmensa mayoría son perdedores como él, y que viven vidas artificiales. Descubre además que la inmensa mayoría de sus posesiones materiales actuales no son producto de su esfuerzo y salario, sino de las tarjetas de crédito. Por lo tanto, ha caído en una nueva esclavitud y esta vez el nuevo amo es el banco. Es así como el individuo cae en el síndrome de la "privación relativa". Ella produce rabia, anomia, falta de identificación, amargura y un intenso grado de frustración.

En otras palabras, los individuos en proceso de modernización se transforman en bombas de tiempo que explotan y producen efectos devastadores para el tejido social. De esta forma, la cohesión social deja de existir y la masa entra en una etapa de profunda anomia y apatía política. Los individuos caen en un sueño y pasividad catatónica que en ocasiones termina por explotar en una nueva rebelión aún más destructiva que las anteriores. Ante esto, el sistema político se defiende con violentas represiones y esto hace que las manifestaciones colectivas disminuyan drásticamente. Pero esta violencia colectiva se transforma entonces en violencia privada dando lugar a una ola de suicidio y de criminalidad descontrolada.

La incapacidad manifiesta de la elite política por resolver las demandas sociales y su brutal represión, da paso entonces a una vigorosa movilización política de las masas. Ellas están dispuestas esta vez a luchar y cambiar las cosas. Los descontentos con el sistema se organizan en movimientos políticos anti elite que mediante sus acciones y protestas van gradualmente debilitando el sistema político hasta hacerlo inoperante. La decadencia política es así imparable y ello desata un ciclo de violencia entre elite y masa, llegando a un punto insostenible donde el viejo sistema político se paraliza y muere. Este momento llega cuando las fuerzas de orden (policía y fuerzas armadas) se rehúsan a reprimir al pueblo y se pasan al bando contrario. Sin defensas apropiadas, la vieja elite es exterminada y/o abandona el país.

Después de la revolución y la muerte del viejo sistema, viene la etapa de la reconstrucción. Históricamente se dan varias formas para reparar el tejido social y crear las bases para una sólida y duradera cohesión social.

Una forma adecuada e históricamente comprobada de controlar y disminuir el caos, el desorden y la violencia producto de la modernización es a través de la creación de instituciones sólidas eficaces y eficientes. Si se elige el gobierno de uno (monarquía), se sigue al líder todo poderoso que consigue crear una dinastía de filósofos reyes que logran canalizar las fuerzas desatadas por el proceso modernizador en forma pacífica y manteniendo la cohesión social. Para lograr esto, el filósofo rey debe gobernar para la mayoría y el bien común. Este fue el caso de las monarquías constitucionales de Inglaterra y los países escandinavos en los últimos tres siglos.

Si se elige el gobierno de varios (aristocracia) o muchos (democracia), el dificultoso proceso de cambio y la marcha hacia la modernidad deben ser dirigidos por poderosos partidos políticos que son respaldados por grandes mayorías y que gobiernan para el beneficio de todos y el bien común. En otras palabras, estas organizaciones políticas han logrado institucionalizarse y a través de esta institucionalización formulan y ejecutan con éxito las políticas públicas que la sociedad demanda. En algunos países de Europa occidental, Estados Unidos, Canadá, Australia y Nueva Zelanda, este es el rol que jugaron los partidos progresistas del siglo XIX y del siglo XX. En la Europa del este y Asia este rol lo jugaron y lo siguen jugando los partidos comunistas de Rusia y China, y los grandes partidos nacionalistas de la India, Japón y los Tigres Asiáticos.

Con la llegada de Reagan y Thatcher al poder en Estados Unidos y en el Reino Unido respectivamente a fines de los años 70 del siglo pasado, se dio comienzo a la actual globalización liberal. Un componente importante de esta ideología planetaria fue introducir la economía de mercado y la democracia liberal al resto del planeta. La 
caída de la Unión Soviética a fines de los 80 destruyó todas las barreras a la ola neoliberal y esta, como un tsunami, se extendió por todo el planeta. En país tras país del tercer mundo se realizaron elecciones y se instalaron seudo democracias liberales al mismo tiempo que se privatizaba la economía. Durante este proceso, en los países afectados, el Estado se redujo y debilitó sustancialmente. Francis Fukuyama anunció que la historia había llegado a su fin. Y todo esto debido a que la evolución de los sistemas políticos había terminado. Ahora el liberalismo reinaba supremo y el capitalismo era la forma adecuada de economía. Esto duraría para siempre y, por lo tanto, la historia del desarrollo civilizacional había llegado a su fin.

La aparentemente imparable ola de democratización neoliberal, celebrada por Fukuyama en los años 90, ahora a comienzos del siglo XXI, ha perdido fuerza y en todo el tercer mundo está en un franco proceso de retroceso. Distintas regiones "recientemente democratizadas" están reaccionando decididamente, eliminando las distorsiones e incongruencia entre cultura y sistema político-económico. Los proclamados "valores universales" difundidos por las elites neoliberales han resultado ser sólo los valores de una ínfima minoría de la humanidad. La cultura noruega únicamente encuentra similitudes en los países escandinavos, Holanda, Suiza, parte de Bélgica, parte de Alemania y la civilización anglosajona constituida por el Reino Unido, Estados Unidos, Canadá, Australia y Nueva Zelanda. El resto del planeta, o sea, la inmensa mayoría de la humanidad, sigue culturalmente apegada a formas tradicionales de gobernabilidad. En otras palabras, profundamente identificadas con la idea del filósofo rey. Esta idea señala que el poder debe ser centralizado, personificado, paternalista e idealizado. Un líder todo poderoso y sabio es muchísimo mas importante que todas las otras instituciones de una democracia que se ha corrompido, debido a la no compatibilidad entre ésta y el carácter nacional de los pueblos donde ella se ha tratado de aplicar.

Los trágicos intentos que los anglosajones han hecho por introducir su sistema a sangre y fuego en el oriente medio han marcado un punto de inflexión. La tragedia del Líbano, Palestina, Irak y Afganistán son testigos de la increíble estupidez política de tratar de imponer un sistema político y económico que no es congruente con su sistema cultural. La reacción a esta barbaridad politológica se está haciendo evidente en todos los rincones del tercer mundo. Los países islámicos eligen democráticamente líderes cuyo público y confesado programa es acabar con la democracia liberal. Lo mismo sucede en Asia, África y América Latina. No obstante, lo que está sucediendo entre los países herederos de la Unión Soviética es aún mucho más importante y significativo.

En este sentido, es sumamente relevante hacer referencia a un reciente manual de historia publicado en Rusia, para ser usado por los estudiantes de ese país. El manual se titula "Una Historia Moderna de Rusia (19452006): Un manual para Profesores de Historia”. El manual empezará a ser usado el próximo año en todas las escuelas de Rusia. Este trabajo ha sido preparado bajo las órdenes del Kremlin y particularmente tiene todo el apoyo del presidente Putin. En varios capítulos este libro se destaca el gobierno de Stalin, señalando que a pesar de la inmensa propaganda en su contra, este gobernante aún tiene el $50 \%$ de aprobación por parte de los rusos. A este líder se le adjudica un papel fundamental en la gran victoria sobre el nazismo. El manual es sumamente crítico respecto a todos los políticos que destruyeron la Unión Soviética a fines de los años 80. El texto reconoce la enorme represión que Stalin impuso sobre la sociedad en su época, pero la justifica como necesaria debido a la guerra fría impuesta por los Estados Unidos. La altísima concentración de poder en manos del dictador era lo que el país necesitaba y reclamaba, obteniendo al final este tipo de gobierno. El manual concluye que este autoritarismo fue una condición básica para la sobrevivencia del país. El manual critica directamente a Gorbachev y lo culpa de ser causante del lento desarrollo económico de los años 80 . También lo acusa de haber perdido la zona de seguridad en el centro y el este de Europa. Se lamenta que hoy día las bases de la OTAN están a sólo una hora de San Petesburgo. Pero aún más criticada es la gestión de los gobiernos liberales que arruinaron y humillaron al país en la década de los años 90. Se argumenta que los rusos liberales creyeron en la benevolencia de los anglosajones, pero que estos los trataron como a una sociedad derrotada e intentaron colonizarla. Los Estados Unidos prosiguieron una política anti rusa tratando de crear satélites en Ukrania, Georgia y los estados del sur de la ex Unión Soviética.

En su parte final, el libro da las pautas para el futuro. El manual recomienda volver a las tradiciones y a la gobernabilidad congruente con el alma rusa. La idea central trata de una nueva movilización de los recursos y particularmente de la consolidación del poder en manos de un líder todopoderoso. La economía debe ser nacionalizada. Se argumenta que si ella depende del capital extranjero y de los términos impuestos por el 
mercado mundial, el país no puede defender sus intereses. El último capítulo del manual expone la teoría de Vladislav Surkov, quien es miembro de la academia de ciencias y jefe de los ideólogos del Kremlin. Surkov argumenta que Rusia necesita un sistema político congruente con su carácter nacional. Rusia debe olvidar las normas de conducta impuesta por los anglosajones, ellas son presiones externas inaceptables. El sistema político y económico que Rusia necesita está predeterminado por su carácter nacional. Este tiene una nostalgia instintiva por la mano dura, justa y poderosa. La centralización del poder, la personificación y la idealización es el motor que dirige la cultura política rusa. Un líder poderoso y sabio es muchísimo mas importante que otras instituciones, de hecho, es la institución más importante.

\section{Conclusión}

Un sentimiento similar al ruso se extiende por todo el tercer mundo. El medio oriente, África y Asia, están reconociendo que sin el apoyo de su base cultural, ningún sistema político puede funcionar adecuadamente. La misma idea se hace cada vez más fuerte también en América Latina. La conclusión de todo esto es obvia: sin respeto a sus valores civilizacionales más sagrados, ninguna sociedad puede funcionar adecuadamente y sobrevivir. Y por supuesto, la cohesión social se convierte en un sueño irrealizable.

Por otro lado, ningún grupo humano se resigna a perder para siempre su sentido de comunidad y tarde o temprano termina por revelarse y cambiar su situación. El ser humano es un animal social y es por ello que abandonó la ley de la selva que impera en el resto de los animales. Creó comunidades y luego civilizaciones hace ya muchos miles de años atrás. La necesidad de fraternidad y socialización está en el ADN del ser humano, si esta necesidad no puede satisfacerse debido a ideologías que imponen un individualismo salvaje, la segregación, la exclusión y la división social; el resultado invariablemente es la inestabilidad extrema y el caos social. Pero a largo plazo, ninguna sociedad sobrevive en un ambiente de desorden constante y así invariablemente se vuelve al orden natural de la cosas.

América Latina al parecer ha decidido poner fin al terrible calvario que se inició a comienzos del siglo XIX. Sueña con una sociedad unida, cohesionada y mucho más justa. Una sociedad que se transforme en una verdadera comunidad y donde sí exista un generalizado sentimiento de simpatía y fraternidad compartido por todos sus ciudadanos. El primer grito de esta nueva revolución lo dio Cuba en 1959 y ahora voces similares se repiten desde el Río Grande a la Patagonia. En pocos años más se celebrará el nacimiento del liberalismo en Iberoamérica. Este fue un triste engendro que nació por equivocación, nunca logró desarrollarse y vivió una vida raquítica, miserable y sometida a decisiones elaboradas en otras latitudes. Ahora viejo y enfermo este defectuoso engendro espera la hora de su muerte. Es de esperar que en el año 2010, después de 200 años de sufrimiento se le dé santa sepultura y se le deje por fin descansar en paz. 